\title{
Difusão científica, comunicação e saúde
}

\author{
Diffusion of science, communication, and health
}

Maria Letícia Galluzzi Bizzo ${ }^{1}$

\footnotetext{
1 Departamento de Nutrição Social e Aplicada, Instituto de Nutrição, Universidade Federal do Rio de Janeiro. Av. Brigadeiro Trompowsky s/n, Bloco J, 2o andar, sala 12, Rio de Janeiro, $R J$ 21941-590, Brasil. galluzzi@ig.com.br
}

\begin{abstract}
The diffusion of science has been identified as an instrument and even as a social movement capable of helping strengthen citizenship and improving the health of populations. The article expounds on the integration of aspects involved in the diffusion of science based on science itself, education, language, and communication, as well as an understanding and social control of science. The article discusses the role of those who produce knowledge in health science as well as those who disseminate it, focusing on such loci as health institutions and schools. The link between various fields of knowledge and practice highlight possibilities and obstacles in the historical and social context.
\end{abstract}

Key words Communication; Health Education; Education; Professional-Patient Relations

Resumo A difusão científica vem sendo apontada como instrumento, e mesmo como movimento social capaz de intermediar o fortalecimento da cidadania e a melhoria da saúde de populações. Propõe-se uma reflexão concernente à integração de aspectos envolvidos na difusão de ciência em saúde, a partir de ponderações englobando ciência, educação, linguagem e comunicação, bem como a compreensão e domínio públicos de ciência. São discutidos elementos relacionados ao papel de quem gera e de quem difunde conhecimento científico em saúde, privilegiando loci como a instituição de saúde e a escola. A articulação entre os distintos campos de saber e fazer envolvidos, revela possibilidades e entraves, potencializados pelo contexto históricosocial.

Palavras-chave Comunicação; Educação em Saúde; Educação; Relação Profissional-Paciente 
O conhecimento científico pode ser formalizado e objetivado para a comunicação, uma forma de difusão científica (Targino, 1997) que pode se dar na educação em saúde em instituições de cuidados à saúde, na escola (por exemplo, no ensino de ciências) ou por outros canais. Embora o conteúdo da comunicação para difusão científica em saúde demande precisão, profundidade, explanação de mecanismos de doença e metabólicos, clareza, estilo conversacional e atualidade científica, quase como via de regra esse conjunto de requisitos está pouco presente (Boyd, 1987). Ganha realce a necessidade de se darem a conhecer os mecanismos de prevenção, instalação, atuação e tratamento das doenças. Fourez (1995) denomina isto de "caixa preta", ou seja, defende a necessidade de se desvendarem, na educação e comunicação científicas, os mecanismos pelos quais os eventos de saúde e doença ocorrem. Saber o como e o porquê, exemplificados através de modelos, seria essencial para a alfabetização em ciência.

Donaldson (1976) explica que, numa situação que demande uma compreensão normal, pode-se utilizar o conhecimento do mundo à nossa volta, mas quando é necessário pensar logicamente, é preciso uma compreensão analítica que requer a formação de suposições. A prescrição de "receitas" não favorece a comunicação; obstaculiza o diálogo, a reflexão e a negociação que um processo comunicacional genuíno poderia compreender (Fourez, 1997). Nesse sentido, as tentativas de educação para a saúde baseiam-se em métodos transmissionais (Sampaio, 2000) e exógenos ao sujeito (Donneys, 1991). A educação pode pontificar-se por ações tecnocráticas, ou, ao contrário, por modelos de comunicação favorecedores do intercâmbio e da auto-gestão (Saviani, 1988), reflexão que pode ser extrapolada para a difusão científica em saúde, seja sob a ótica do ensino de ciências nas escolas, seja na atenção primária em instituições de saúde. Essa educação veio se caracterizando por ênfases que passam do foco quase exclusivo nos processos biológicos das doenças ao foco no comportamento individual, marcado por recomendações de condutas apropriadas e desvinculado do contexto sócio-econômico e de outras intrincadas interrelações, que muitas vezes são a causa direta ou indireta da doença (Lima, 2000). A reflexão sobre essa realidade auxilia na tomada de consciência das condições e no engajamento em transformá-la.

A compreensão tácita não pode ser reduzida à sua articulação explícita, porque ela pode ser articulada por um número indeterminado de sistemas de linguagem: quando se observa uma figura, a cognição exige um contexto; essa exigência torna impossível localizar de modo preciso o significado do significante, e nem o significado de palavras pode ser entendido isoladamente de uma linguagem, uma comunidade ou um mundo (Dennett, 1991). A esse respeito, tanto o relativismo cognitivo quanto o relativismo epistemológico trazem luz sobre a questão (Davidson, 1990) e reflexões para a prática da difusão científica. A essência paternalista do modelo de educação em saúde, predominante entre nós, conta com o pouco questionamento da população, em parte devido à baixa escolaridade (Sampaio, 2000). Conhecendo melhor suas próprias condições de saúde (incluídas causas e conseqüências), o indivíduo poderia atuar como agente do próprio desenvolvimento, e não como receptor passivo de ajuda, pois a mera prescrição de comportamentos ou atitudes torna os indivíduos mais dependentes, por vezes com perda da própria autonomia (Rice \& Candeias, 1989). A superação desse modelo paternalista e informativo implicaria em adotar um processo comunicacional bidirecional em lugar do unidirecional, transpondo o direito puro e simples à informação e atingindo inclusive as decisões sobre o tratamento (Caprara \& Franco, 1999).

Evidencia-se no contexto de saúde o paciente reproduzindo o discurso médico, sem por vezes compreender seu significado (Martins, 1991); nessa relação profissional de saúde-paciente há uma tendência a buscar uma proteção mágica que justifica a submissão absoluta ao tratamento invasivo e agressivo: regressão, infantilização, submissão e dependência surgem nessa tentativa do paciente de dominar a doença (Canella, 1989). Em contraponto, a ausência ou insegurança quanto a conhecimentos e cuidados de saúde contribui para sentimentos de incapacidade, abandono e ansiedade (Seligman, 1975). Em nossa sociedade, chega-se a observar uma deseducação científica promovida pela mídia (Candlish, 1996), especialmente na área de alimentação e saúde, sendo mesmo denominada de "educação para a doença" (F. Lefèvre, 1980, comunicação pessoal). "Nota-se, não raro, que uma descoberta no campo da Biologia, da Psicologia e da Sociologia, ao invés de funcionar como subsídio aos propósitos da didática, acaba transformandose em um fim em si" (Nérici, 1989:23) notandose que a articulação entre o saber médico-biológico e a pedagogia não tem sido bem-sucedida (Sampaio, 2000). Entre as sociedades indígenas, a educação valoriza o conhecimento do corpo (Pilletti, 1991) mas em nossa sociedade, o ensino formal de ciências, nas escolas particu- 
larmente, apresenta seu eixo deslocado do contexto da existência da vida (Ribeiro et al., 1997).

A educação representaria uma herança recebida por cada geração em relação ao patrimônio científico-cultural da humanidade (Fourez, 1997); entretanto, os modelos científicos de ensino de ciências, aí contidos os conteúdos de saúde, não estão representados nesse conjunto, sequer de maneira minimamente satisfatória. Os objetivos dessa educação científica já foram definidos como "ensinar ciência de modo relevante e democrático; tomar o contexto como fonte para o ensino de ciência; propiciar a formação do espírito científico" (Vale, 1996:15), ou "desenvolvimento do pensamento lógico e vivência do método científico" (Martins, 1990:48), e as diretrizes propostas para a educação científica na escola como: compreender como as teorias científicas são geradas, incluindo o uso de modelos explicativos; desenvolver uma compreensão das idéias científicas-chaves; compreender como o cientista trabalha; compreender como as evidências científicas são geradas e avaliadas; vivenciar processos práticos; adquirir certas habilidades experimentais; desenvolver a capacidade de observação e manipulação científica; avaliar evidências na tomada de decisões e solucionar problemas; aprender algumas coisas sozinho; alimentar a curiosidade e estar motivado a manter interesse em ciência; compreender a natureza não-definitiva do conhecimento científico; entender os valores sociais envolvidos, inclusive as implicações éticas da ciência (Association for Science Education, 1998). Não obstante, mesmo nos países desenvolvidos, critica-se a falta de relevância para os alunos do modelo de educação em ciências (Morgan, 1993).

Das políticas governamentais às práticas na sala de aula, dos cientistas aos planejadores, das instituições de ensino à sociedade como um todo, todos têm sido culpabilizados pelas deficiências (Ribeiro, 1964). Um fórum mundial clarificou uma aspiração generalizada de tornar essa educação mais ligada à vida do diaa-dia (Fourez, 1997). Aponta-se, no Brasil, a necessidade de uma ampla alfabetização científica da sociedade (Rutherford, 1999); no entanto, nota-se que, paradoxalmente, recai sobre os países com menor participação na geração de ciência a responsabilidade por educar um maior contingente de jovens (Lannes et al., 1998). Particularmente entre os jovens constata-se uma compreensão pobre de ciência; para Candlish (1996), compreender ciência implica não só em entender como a ciência é fundamentada e regida, mas igualmente como o cientista trabalha e pensa.
O método científico tradicional inclui os movimentos de pergunta, hipótese, experimento e resposta (Bhargava, 1995). Porém o dinâmico surgimento de novos conhecimentos requer contínuas mudanças na forma como se ensina ciências (Lannes et al., 1998). A falha na articulação entre saúde e educação é, em parte, responsável pelo não reconhecimento público de ciência como um bem a serviço do estado de saúde (Sampaio, 2000). Postula-se que uma modificação nos paradigmas da chamada "medicina científica" conferiria maior importância à educação e promoção dos valores da vida (Fourez, 1995). Em recomendações da comunidade científica americana para a política de ensino de ciências, destacam-se, dentre os conteúdos propostos como relevantes, a saúde física e o desenvolvimento e funcionamento do organismo humano (Rutherford, 1999). Esse enfoque não se concentraria sobre um indivíduo "abstrato", separado da realidade afetiva e social em que vive, mas sobre uma pessoa integrada ao seu meio (Fourez, 1995). Considerações epistemológicas apontam as possibilidades de fusão do pensamento positivista - com seus fatos objetivos, estabelecidos e quantificados - com o senso de que o mundo social é ativamente construído por seres humanos, e aí os conhecimentos de saúde (Milburn, 1997). Nesse sentido, os estudos populacionais de saúde têm contribuído muito pouco, inclusive para as políticas e o estado de saúde das populações, particularmente nos países em desenvolvimento, e muitas recomendações apontam para a necessidade de os estudos de pesquisa aplicada disponibilizarem as informações científicas e manterem canais de comunicação permanente com a população (Tollman \& Zwi, 2000).

Tanto na área de educação quanto na de saúde, o enfoque predominantemente curativo em detrimento do preventivo, a ausência de integração entre os educadores e os membros da comunidade, a falta de abordagens multidisciplinares, o ceticismo dos profissionais em trabalhar de forma participativa com a comunidade e a falta de qualificação desses profissionais são entraves à comunicação no âmbito da difusão científica e educação em saúde (Rice \& Candeias, 1989). Como tem se evidenciado cada vez mais problemático para as instituições de saúde atender à demanda crescente em nível de assistência primária, mostra-se patente a necessidade do fortalecimento do relacionamento entre o sistema formal de saúde e a comunidade (Rice \& Candeias, 1989). A ausência de um sistema de vigilância de saúde da população eficiente somente reforça a necessidade de difusão científica. 
Com a disseminação da AIDS, a partir da década de 80, a preocupação em realizar ações educativas mais realísticas provocou uma explosão no desenvolvimento de novos materiais educativos, alguns dos quais mostrando claramente uma tendência em construir modelos de comunicação mais profícuos (Sampaio, 2000). Rotineiramente, entretanto, pacientes em geral e seus familiares avaliam a comunicação científica em saúde como excessivamente técnica, de linguagem incompreensível, muito geral e desprovida de discussão acerca do processo das doenças (Cowles \& Rodgers, 1997). Segundo Mannheim (1974:145), "a ciência tem um estilo de pensamento não-democrático": "a ciência manipula as coisas e se recusa a habitálas" (Abril Cultural, 1980:193). Porém, a atuação no mundo e a interpretação dos estímulos, exigem uma participação individual e interna. A abordagem pode perfeitamente se dar em linguagem não-técnica; a teoria da relatividade elaborada por Einstein, por exemplo, é composta por complicadas equações matemáticas, mas suas idéias são simples, tendo sido Einstein um dos cientistas que mais se voltaram para a questão da difusão científica (Bizzocchi, 1999). A Internet tende a se tornar um dos principais veículos de informação científica nos países desenvolvidos e nas classes mais privilegiadas do terceiro mundo (Bizzocchi, 1999), mas nisto o contraste social entre os vários "brasis" impõe uma profunda lacuna (Targino, 1997).

Um dos grandes desafios da ciência é ser amplamente difundida, sem perder a precisão; porém, o rigor científico não precisa ser sinônimo de hermetismo na difusão de ciência, pois o jargão científico torna praticamente impossível ao leigo decodificar um texto científico; “o que interessa ao público leigo não são os textos científicos, mas as idéias que eles contêm" (Bizzocchi, 1999:31). A linguagem não precisa ser uma barreira à divulgação das idéias, pode ser uma ponte. Apesar disso, o modelo de comunicação vigente já foi denunciado como meio de "interpor a fala do especialista entre a experiência real de cada um e sua vida. Essa fala gera o sentimento individual e coletivo da incompetência. Essas falas científicas têm por finalidade tornar a realidade controlável, previsível, determinando o que cada um de nós deve ser para, simplesmente, poder ser" (Chauí, 1983:58).

Dado que a sensibilização e a "estimulação" são requisitos à adequação da abordagem, embora admitindo-se que toda educação é uma auto-educação, evidencia-se que a sociedade "cria o clima, proporciona os meios e determina os objetivos e a orientação desse proces- so. O indivíduo educa-se sempre para determinada situação, por meio de uns tantos recursos técnicos, materiais e humanos que a sociedade lhe prepara" (Ribeiro, 1964:72). Instrumentos e técnicas podem auxiliar a mediar situações e conceitos no ensino de saúde com ganhos efetivos (L'Abbatte, 1997). Isto requer profissionais treinados (Fourez, 1997), porém no Brasil, a insuficiência de treinamento e recursos gera professores apáticos (Martins, 1990) para propiciar sensibilização, motivação ou um verdadeiro enlace comunicacional. Nascem os "silêncios" na comunicação, tanto por parte de quem "ensina”, quanto de quem "aprende": silêncio de dificuldade de comunicação, silêncio de desinteresse, silêncio de resistência e bloqueio emocional, silêncio de desconfiança, assim como gestos e sinais da comunicação nãoverbal que traduzem esse contexto (Castilho, 1998).

Cada situação requer a invenção de um modelo de ensino. A didática literalmente significa "a arte de ensinar" (Nérici, 1989:23); como tem servido à comunicação e difusão de ciência? Para Dürkheim (1978), hoje a ciência ocupa o lugar outrora preenchido pela arte. Os primeiros educadores foram os poetas, começando por Homero, e a educação clássica da Grécia e Roma antigas destacou-se pelo caráter humano; a separação da escola em relação à vida do dia-a-dia principiou apenas na Idade Média (476-1453), tornando-se a própria atividade de ensinar especializada (Martins, 1990). A evolução das civilizações acompanhou-se da apropriação e domínio do conhecimento por distintos grupos: técnicas de cultivo, sobrevivência, cura de doenças; dicotomizaram-se o saber erudito e o popular, o caráter humanístico quase que se dissipou. Com a ascenção da sociedade burguesa ocidental, a ciência passou a ser cooptada pelo poder econômico (Boyd, 1987). A abrangente sabedoria da Renascença foi trocada pela pesquisa especializada, restrita às universidades e não mais difundida (Bizzocchi, 1999), instalando-se um saber-objeto, uma elitização que dogmatizou a comunicação e acesso à ciência, autorizando uma dominação nascida da não-comunicação. Com o positivismo do século XIX, o conceito de utilidade da ciência para alcance da satisfação material do ser humano relegou a pesquisa básica a segundo plano (Bizzocchi, 1999). Com a Revolução Industrial, a burguesia "modernizou" a escola: a ênfase no saber literário e na filosofia foi substituída pelas chamadas "disciplinas científicas” (Pilletti, 1991), cabendo pensar no porquê da substituição em detrimento de uma "comunhão". "É uma pena que tantos cientistas 
tenham uma relação de trabalho tão pobre com as humanidades" (Arnold, 1997:211).

Se a educação varia com o tempo e o meio (Targino, 1997), parece, entretanto, prevalecer um aspecto comum: inculcar idéias, sentimentos e práticas (Pilletti, 1991). Na visão de Dürkheim, não é possível postular uma educação ideal (Dürkheim, 1978), pois ela toma a forma da estrutura das sociedades. Imagina-se que os homens de cada tempo organizam a sociedade voluntária e conscientemente para realizar fins determinados. A própria trajetória da educação no Brasil ganhou contornos diversos ao longo do tempo: no Brasil-Colônia, norteou-se pelos interesses da metrópole; no Império, a economia agro-exportadora não suscitou ao Estado criar um sistema escolar; no período industrial da República, os interesses por mãode-obra especializada direcionaram a política educacional; finalmente, chegou-se ao modelo capitalista, que fez a democratização do ensino superior e a profissionalização do 2 o grau, porém com objetivos e formas discutíveis (Martins, 1990). Na atual sociedade capitalista, por exemplo, predomina a orientação individualista na educação (Pilletti, 1991). Analisados sob este prisma, os sistemas educativos sempre parecem erros, totais ou parciais. A história do magistério brasileiro tem sofrido interferências que afetam a qualidade desse ensino: a seletividade negativa (tornou-se um campo profissional que em geral atrai "sobras" de outros); remuneração deficiente, desmotivação docente, insuficiente reciclagem e atualização (Martins, 1990). A qualidade dos conteúdos e da comunicação é afetada.

Mesmo levando-se em conta que a educação pode exercer papéis diferentes dentro da sociedade (Luckesi, 1986), sua finalidade específica seria a de pôr à disposição o patrimônio cultural da humanidade; pressupõe-se que esse patrimônio, no que tem de mais importante, esteja concentrado nos currículos escolares, mas estes geralmente não incluem as experiências humanas mais significativas, e sim fragmentos, muitas vezes desconexos, dessas experiências (Pilletti, 1991), num obstáculo adicional à comunicação. Para a sociologia da educação, os comportamentos familiares desempenham um papel determinante na socialização, mas não são os modelos de referência mais importantes na educação propriamente dita, havendo um papel crucial da escola (Bizzocchi, 1999). "São as instituições educacionais, através de todas as suas manifestações concretas, que estabelecem e regulamentam os mecanismos de transferência cultural, de especialização de hierarquias, das formas de conhecimento social- mente úteis, do domínio das técnicas de ação social, enfim, de todo este verdadeiro universo cultural que constitui o conjunto dos conhecimentos que o homem moderno domina" (Toscano, 1984:13). Nesse sentido, a ciência seria um requisito fundamental: "A escola será tanto mais eficiente quanto mais estiver aberta às condições do país e do mundo em que vivemos. $O$ interesse pelos problemas atuais que afligem a humanidade não poderá deixar de existir dentro da escola, na medida em que esta pretende formar pessoas para atuarem de forma construtiva na solução desses problemas; a civilização é instigada a superar o desafio da busca pelo conhecimento, pela democracia e pela educação universal, num caráter interdependente" (Rutherford, 1999:856). Deixando de lado tudo o que a educação tem sido, poderíamos indagar o que ela deve ser (Targino, 1997).

Numa meta-análise, a função social da ciência na produção de conhecimento seria necessária ao desenvolvimento da sociedade (Vale, 1996). Mas os caminhos da ciência são desenhados quase que exclusivamente pelos interesses dos cientistas, induzindo a pensar que a forma como vêem o mundo seria a única correta ou possível (Fourez, 1997). As comunidades científicas são responsáveis pela sua própria perpetuação, por meio do treinamento dos novos cientistas, e são as únicas aceitas pelos seus membros como árbitros de sua prática. Em seu interior a comunicação é relativamente suficiente, mas fora dela é escassa, dado o alto grau de especialização e de diferenciação de sua linguagem (Khün, 1991), dificultando a comunicação das idéias científicas. Não obstante, sustenta-se que a educação científica da sociedade deve ser suscitada pela academia ( $\mathrm{Ru}$ therford, 1999). Nos países desenvolvidos, há projetos de estreita cooperação entre cientistas e educadores no âmbito da difusão científica (Lannes et al., 1998) e no Brasil, ressalta-se o papel da universidade na educação continuada dos professores de Segundo Grau (Ramos, 1990/1991). Todavia, a universidade brasileira é qualificada como indiferente às preocupações da comunidade, com raras exceções (Targino, 1997). Chauí (1983:62), aponta que " $a$ universidade está estruturada de tal forma que sua função é dar a conhecer para que não se possa pensar; adquirir e reproduzir para não criar; consumir, em lugar de realizar o trabalho da reflexão", denunciando um modo de comunicação restritivo, reforçado por um segundo plano ameaçador: "a educação em ciência é por vezes um tema que intimida mais os especialistas do que a ciência em si mesma" (Chauí, 1983:59). 
Não há participação da comunidade científica nas políticas de educação em ciências, e a falta de verbas e o tamanho reduzido dessa comunidade contribuem para obstaculizar iniciativas (Lannes et al., 1998). Questiona-se o peso social que essa comunidade possui para influenciar as políticas de ensino e pesquisa, e o ensino e comunicação de ciência no país. Por outro lado é sublinhado o fato de que os recursos destinados à ciência provêm do Estado ou do grande capital privado, questionando-se se essas instituições têm genuíno interesse na difusão científica (Bizzocchi, 1999). Pouco se sabe acerca de como as crenças dos leigos e da sociedade se relacionam com as dos cientistas (Cooter \& Pumfrey, 1994), mas "a idéia de que a ciência é monolítica, incompreensível, desprovida de alma, e basicamente má para nós, forma o núcleo de um paradoxo central dos nosso tempos: a ciência se tornou menos popular $e$ mais temida, apesar de sua influência e relação intrínseca com a nossa vida e atividades quotidianas; menos perseguida e acalentada, embora cada vez mais essencial à base da educação de todos os seres humanos" (Gould, 1998:812).

A crítica da ciência nasce até dos meios científicos: quando examinamos a ciência contemporânea, dificilmente podemos vê-la como instrumento de libertação e, muito menos, como um pensamento criador que nos torna mais reais e mais ativos. Pelo contrário, condição e fruto do "progresso", a ciência tornou-se poderoso elemento de intimidação sócio-política, através da noção de competência. "Poderíamos resumir a noção de competência no seguinte refrão: não é qualquer um que pode dizer qualquer coisa a qualquer outro em qualquer lugar e sob qualquer circunstância" (Chauí, 1983:58).

Khün (1991), analisando as origens e propósitos da ciência, valorizou as decisões (muitas vezes não-intencionais, não-racionais, mas nascidas também do acaso ou da irracionalidade) pelas quais uma disciplina toma sua forma. Uma ciência nasce em uma rede de interesses que posteriormente é fácil analisar (Fourez, 1995). Mas a construção de seus paradigmas, de seu conjunto de regras e das representações mentais e culturais que regem seu surgimento, não são culturalmente neutros. Feyerabend (1975) refere-se à ciência como "a religião dos cientistas", e sugere um mesmo modus operan$d i$ entre as transformações científicas e as religiosas: retórica, carisma e apelo, gerando um modelo comunicacional controverso. "Os intelectuais, com a elitização da ciência, terminaram isolados, inatingíveis, desconectados do contexto social e não compreendidos pela comunidade em benefício da qual a atividade científica se justifica" (Bizzocchi, 1999:29). Os historiadores de ciência ressaltam como o conhecimento científico foi mantido distante da sociedade pelos próprios cientistas, para resguardar seu status social; a ciência sedimentou-se longe da sociedade, guardando a história das idéias científicas uma enorme distância da sociologia do comportamento coletivo (Cooter \& Pumfrey, 1994). No contexto brasileiro, questiona-se mesmo a quem servem as pesquisas (Chauí, 1983).

A alfabetização em ciência é tomada como uma contribuição à democracia, ao socializar o conhecimento científico de forma a encorajar o debate público e dificultar a centralização de decisões nas mãos de tecnocratas, e é tomada como humanística, ao auxiliar que cada indivíduo aproveite todo o seu potencial, inclusive biológico (Fourez, 1997), sendo tida como instrumento de melhoria da qualidade de vida (Ribeiro et al., 1997). Fourez (1997) chega a defini-la como um movimento social. Implicaria em conferir aos indivíduos: certa autonomia; uma certa capacidade de comunicação; algumas formas de lidar com situações específicas e de negociar; isto inclui o pensar em ciências e o agir em saúde. Para ele, o conhecimento útil deve ser traduzido para as representações da vida quotidiana, inclusive para a tomada de decisões - abarcando resoluções que afetam a saúde dos indivíduos, servindo à autonomia e ao manejo de situações (Fourez, 1997).

A democratização do conhecimento científico conferiria um dado poder, ao fornecer conhecimento do qual a sociedade pode se servir (Bacon, 1984; Bizzocchi, 1999). Por conhecimento não se entenderia um puro arquivamento de informações, mas "uma compreensão ordenada do mundo, que dá poder de ação adequado e eficaz" (Luckesi, 1986:30). "Confere um verdadeiro conhecimento, no sentido de que a representação do mundo por ele fornecido permite agir. A vulgarização científica traz implicações sócio-políticas importantes. Se o conjunto da população não entende nada de ciência, será pouco capaz de participar dos debates relativos às decisões que lhe dizem respeito. Mas se a vulgarização científica der às pessoas conhecimentos suficientemente práticos para que elas possam ponderar sobre as decisões com melhor conhecimento de causa, essa vulgarização é uma transmissão de poder" (Fourez, 1995:221); seria o "poder transformador" do conhecimento (Vale, 1996). Saber significaria um aumento nas potencialidades sociais e econômicas (Fourez, 1997); "o mundo inteiro vem sendo, atualmente, empolgado por mudanças tão rápidas, que o atraso cultural se transforma em 
verdadeira crise" (Lenhard, 1981:50). O desvendamento da realidade é citado como um instrumento de conquista da cidadania por dar suporte a decisões.

Os conteúdos não só são necessários para a formalização da mente, mas possuem um valor em si mesmos; são o resultado do esforço da humanidade em compreender o mundo e caracterizados como um direito individual (Luckesi, 1986). Se, de um lado, os próprios cientistas pontuam a superioridade da qualidade dos conteúdos e da abordagem sobre a quantidade no ensino de ciências (Rutherford, 1999), de outro, as críticas a esse ensino se referem a excesso de conteúdo, predomínio de atividades de memorização sobre as de compreensão, centralização excessiva em livros-textos, inadequação à realidade e ao contexto social e profissionais mal-treinados (Ribeiro, 1964).
Os resultados científicos permanecem à margem da vida, ou são apresentados como verdades absolutas. No entanto, são apenas modelos, construídos por e para seres humanos, com o objetivo de lidar com a realidade (Fourez, 1997), seja qual for o sentido que se queira dar a esta. Se numa pretensa difusão científica "o que me é dado sob a aparência de saber não é sequer o próprio saber, mas sua caricatura banalizada e vulgarizada; recebo, sob a forma de informação, uma versão degradada de um saber que desconheço tanto no nível de sua produção quanto no de seu consumo" (Chauí, 1983: 59), talvez o caminho não esteja em meramente condenar conceitos e práticas antigos, mas, em ponderando os percursos que a história construiu, inventar um novo modelo de criar e comunicar ciência para a saúde do homem.

\section{Referências}

ABRIL CULTURAL, 1980. Merleau-Ponty. Coleção Os Pensadores. São Paulo: Editora Abril Cultural.

ABRIL CULTURAL, 1984. Francis Bacon. Coleção Os Pensadores. São Paulo: Editora Abril Cultural.

ARNOLD, W. N., 1997. The hard sciences and the humanities. Biochemical Education, 25:211-216.

ASSOCIATION FOR SCIENCE EDUCATION, 1998. Science education for the year 2000 and beyond. Education in Science, 176:17-20.

BHARGAVA, P. M., 1995. New challenges in the teaching of modern Biology. Biochemical Education, 23:120-122.

BIZZOCCHI, A. L., 1999. Culture and pleasure: The place of science. Ciência e Cultura, 51:26-31.

BOYD, M., 1987. A guide to writting effective patient education materials. Nursing Management, 18:5664.

CANDLISH, J. K., 1996. Report of the meeting on perceptions of biochemistry by the public, the press and the politicians. Biochemical Education, 24:2.

CANELLA, P. R. B., 1989. Grupos - Pré-atendimento, sala de espera e enfermaria. Femina, 23:910-917.

CAPRARA, A. \& FRANCO, A. L. S., 1999. A relação paciente-médico: Para uma humanização da prática médica. Cadernos de Saúde Pública, 15:45-55.

CASTILHO, A., 1998. A Dinâmica do Trabalho de Grupos. Rio de Janeiro: Editora Qualitymark.

CHAUÍ, M. S., 1983. O que é ser educador hoje? Da arte à ciência: A morte do educador. In: $O$ Educador - Vida e Morte (C. R. Brandão, org.), pp. 51-70, Rio de Janeiro: Editora Graal.

COOTER, R. \& PUMFREY, S., 1994. Separate spheres and public places: Reflections on the history of science popularization and science in popular culture. History of Science, 32:237-252. 
COWLES, K. V. \& RODGERS, B. L., 1997. Struggling to keep on top: Meeting the everyday challenges of AIDS. Quality Health Research, 7:98-113.

DAVIDSON, D., 1990. The structure and content of truth. Journal of Philosophy, 87:64-71.

DENNETT, D., 1991. Consciousness Explained. Philadelphia: Little, Brown \& Co.

DONALDSON, M., 1976. Children's Minds. London: Fontana.

DONNEYS, M. E. C., 1991. Educación para la salud: Aspectos metodológicos. Educación Médica y Salud, 25:194-202.

DÜRKHEIM, E., 1978. Educação e Sociologia. São Paulo: Editora Melhoramentos.

FEYERABEND, P. K., 1975. Against Method. London: New Left Books.

FOUREZ, G., 1995. A Construção das Ciências. Introdução à Filosofia e à Ética das Ciências. São Paulo: Editora UNESP.

FOUREZ, G., 1997. Scientific and technological literacy as a social practice. Social Studies on Science, 27:903-922.

GOULD, J. S., 1998. The great asymmetry. Science, 279:812.

KHÜN, T., 1991. A Estrutura das Revoluções Científicas. São Paulo: Editora Perspectiva.

L'ABBATTE, S., 1997. Comunicação e educação: Uma prática de saúde. In: Agir em Saúde: Um Desafio para o Público (E. E. Merhy \& R. Onocko, org.), pp. 267-292, São Paulo: Editora Hucitec/Buenos Aires: Lugar Editorial.

LANNES, D.; FLAVONI, L. \& DE MEIS, L., 1998. The concept of science among children of different ages and cultures. Biochemical Education, 26:199.

LENHARD, R., 1981. Sociologia Educacional. São Paulo: Editora Pioneira.

LUCKESI, C. C., 1986. Educação e cidadania: Contribuições da tecnologia educacional. In: 18o Seminário Brasileiro de Tecnologia Educacional, Anais, p. 30, Rio de Janeiro: Associação Brasileira de Tecnologia Educacional.

MANNHEIM, K., 1974. A democratização da cultura. In: Sociologia da Cultura (K. Mannheim, org.), pp. 34-47, São Paulo: Editora Perspectiva.

MARTINS, D. M., 1991. Consulta coletiva: O espaço da mulher. Cadernos de Saúde Pública, 7:267-283.

MARTINS, J. P., 1990. Didática Geral. São Paulo: Editora Atlas.

MILBURN, K., 1997. Combining methods in health promotion research: Some considerations about appropriate use. Health Education Journal, 54: 347-355.
MORGAN, K., 1993. Teacher and leadership education for scientific and technological literacy. Paris: United Nations Educational Scientific and Cultural Organization.

NÉRICI, I. G., 1989. Didática Geral Dinâmica. São Paulo: Editora Atlas.

PILLETTI, N., 1991. Sociologia da Educação. Rio de Janeiro: Editora Ática.

RAMOS, M. C. M., 1990/1991. Formação continuada do professor. Didática, 26/27:83-86.

RIBEIRO, J. Q., 1964. Formas do processo educacional. In: Educação e Sociedade (L. Pereira \& M. M. Foracchi, org.), pp. 70-79, São Paulo: Companhia Editora Nacional.

RIBEIRO, M. G.; TELES, M. E. \& MARUCH, S. M. G., 1997. Morphological sciences museum: A multidisciplinary approach to the human body improves the teaching of science. Ciência e Cultura, 49:169-177.

RICE, M. \& CANDEIAS, N. M. F., 1989. Padrões mínimos da prática da educação em saúde - Um projeto pioneiro. Revista de Saúde Pública, 23:347351.

RUTHERFORD, F. J., 1999. The advancement of science in Brazil. Anais da Academia Brasileira de Ciências, 71:855-860.

SAMPAIO, F. T., 2000. Passado terminal: Cinco séculos de tentativas não foram suficientes para aproximar a saúde pública brasileira das salas de aula. Educação, 9:62-63.

SAVIANI, D., 1988. Educação: Do Senso Comum à Consciência Filosófica. São Paulo: Editora Cortez.

SELIGMAN, E., 1975. Depression and learned helplessness in man. Journal of Abnormal Psychology, 84:530-533.

TARGINO, M. G., 1997. The internet and society: Just another dream? Ciência e Cultura, 49:252-262.

TOLLMAN, S. M. \& ZWI, A. B., 2000. Health system reform and the role of field sites based upon demographic and health surveillance. Bulletin of the World Health Organization, 78:125-128.

TOSCANO, M., 1984. Introdução à Sociologia Educacional. Petrópolis: Editora Vozes.

VALE, J. M. F., 1996. Educação científica e sociedade. Didática, 31:9-14.

Recebido em 27 de julho de 2000

Versão final reapresentada em 27 de fevereiro de 2001

Aprovado em 5 de março de 2001 